\title{
OS FEITIÇOS VOCABULARES DE UM ESCRITOR
}

Denise Salim Santos (UERJ)

Resumo: Neste artigo analisa-se o vocabulário empregado pelo escritor João Ubaldo Ribeiro no romance $O$ feitiço da ilha do Pavão (doravante, FIP, 1997), buscando-se observar a palavra empregada e seu efeito discursivo. Valorizam-se neste estudo as unidades lexicais que demonstram a artesania do escritor em selecionar formas que configuram o léxico como um todo construído historicamente. Vê-se em seu texto o emprego de formas pertencentes ao repertório erudito, ao repertório comum, passando pelo léxico de especialidade e chegando ao uso popular das palavras. Para tanto, faz-se o levantamento das formas nominais - substantivos e adjetivos - e verbos que marcam não só as intenções discursivas ali presentes, bem como a tradição lexical da língua portuguesa, delimitada pelas condições de produção do discurso. Como referências, trazemos os dicionários gerais - Dicionário Houaiss da Língua Portuguesa (2009), Dicionário Aurélio da Língua Portuguesa (2014) e os teóricos Lapa (1988), Turazza (2005), Pretti (2003), Sandmann (1992), Antunes (2010) e Maingueneau (2006). Embora seja sabido que a construção semântica de um texto não depende única e exclusivamente de cada unidade lexical, mas também dos arranjos gramaticais com que são construídos os enunciados, observou-se o cuidado do escritor em construir um campo léxico-semântico que desse consistência coesiva ao texto a partir da exuberância do vocabulário amplo e diversificado por ele empregado.

Palavras-chave: Léxico; Substantivos; Adjetivos; Efeitos discursivos; João Ubaldo Ribeiro; O Feitiço da Ilha do Pavão.

Abstract: This article analyzes the vocabulary employed by João Ubaldo Ribeiro writer in the novel O feitiço da ilha do Pavão (FIP, 1997), seeking to observe the maid word and its discursive effect. Are valued in this study the lexical units that demonstrate the craftsmanship of the writer in selecting forms that make up the lexicon as a whole historically constructed. It is seen in his text the use of forms belonging to the classical repertoire, the common repertoire, through specialty lexicon and coming to popular use of words. For this purpose, it is lifting the nominal forms - nouns and adjectives - and verbs that mark 
not only present there discursive intentions, as well as lexical tradition of Portuguese, bounded by the speech production conditions. The references were obtained in the general dictionaries - Dicionário Houaiss da Língua Portuguesa (2009), Dicionário Aurélio da Língua Portuguesa (2014) and the Lapa academics (1988), Turazza (2005), Pretti (2003), Sandmann (1992), Antunes (2010) and Maingueneau (2006). While it is known that the semantic construction of a text depends not solely of each lexical unit, but also the grammatical arrangements with which the statements are made, there was the writer's careful to build a lexical-semantic field to give cohesive consistency the text from the exuberance of the broad and diverse vocabulary for it employee.

Keywords: Lexicon; Nouns; Adjectives; Discursive effect; João Ubaldo Ribeiro; O Feitiço da Ilha do Pavão.

\section{PRELIMINARES}

O texto que trago a esta publicação é um recorte de minha tese de doutoramento cujo título é Tradição e transgressão vocabular: um estudo do vocabulário em "O feitiço da Ilha do Pavão" (UERJ, 2008). Busquei identificar na seleção vocabular empreendida pelo autor João Ubaldo Ribeiro, não só a riqueza de um repertório peculiar a quem desenvolveu desde muito cedo o amor pela leitura dos clássicos da literatura universal e nacional, mas também a versatilidade em fazer das palavras como instrumentos de alta discursividade representativos da sua maneira de olhar o Brasil na sua constituição histórica e, principalmente, social.

A ilha do Pavão é uma ilha-país onde não deveria haver mais lugar para desigualdades ou preconceitos de quaisquer 
espécies. A justiça social desempenharia a função de sustentáculo da liberdade de cada habitante da Assinalada Vila de São João Esmoler do Mar do Pavão e de outras tantas vilas que compõem esse mundo imaginário, espaço no qual a ação narrativa acontece.

Logo no primeiro capítulo do livro, João Ubaldo, pela voz do narrador em terceira pessoa, empenha-se em apresentar ao leitor a ilha em seus caracteres físicos, seus habitantes, o espaço em que vivem, as histórias que a cercam de mistérios e magias, enfim, a vida da Assinalada Vila de São João Esmoler do Mar do Pavão, fundada no dia 23 de janeiro. Ali vivem orgulhosos e felizes os joaninos ou os assivissojoemapaenses, segundo se prefira menor ou maior formalidade de tratamento:

A Assinalada Vila de São João Esmoler do Mar do Pavão não parece evidenciar qualquer singularidade de monta. Observaria o visitante apressado que os joaninos são iguais a toda gente, ocupados em afazeres dos quais toda gente se ocupa. Talvez lhe cause um pequeno espanto ver como homens, mulheres e crianças, brancos e negros, bem-postos e pobres, diferentemente de outras terras, abraçam o uso de tomar banhos de mar, às vezes durante toda manhã ou mesmo todo dia, entre grandes folguedos e algazarras sem que constipem ou lhes advenha algum mal 
da excessiva infusão em humores salsos. Possivelmente estranhará ver negros calçando botas, sentando-se à mesa com brancos, tuteando-os com naturalidade e agindo em muitos casos como homens do melhor estofo e posição financial, além de negras trajadas como damas e de braços dados com moços alvos como príncipes do norte. (FIP, p. 17)

O texto deixa transparecer a tentativa do escritor em criar dois mundos paralelos, baseando-se no contexto sóciohistórico de um Brasil colonial e no mito da ilha da Fortuna, que se confunde com as imagens de paraíso terrestre, presente no mito fundador do Brasil, haja vista a primeira carta de Pero Vaz de Caminha e as crônicas enviadas a El-Rei de Portugal à época do descobrimento.

Segundo Antunes,

o vocabulário "de um texto concorre para o estabelecimento de sua coerência, para definição de sua unidade [...]. A escolha das palavras já está, grosso modo, definida desde a seleção do tema, desde a direção da argumentação ou do objetivo pretendido". (ANTUNES, 2010, p. 179-180)

Partindo da visão geral do capítulo em análise, ainda que pareça óbvia a informação, predominam quantitativamente os itens do vocabulário comum, cujo emprego dá suporte ao leitor, para construir o sentido daquelas palavras e 
expressões que não Ihes são frequentes no uso ou mesmo em textos outros.

Mas isso não quer dizer que as palavras que não pertençam ao repertório do leitor sejam menos relevantes por constituírem formações neológicas tais como: (a) assivissojoemapaenses, substantivo, por processo de conversão a partir de adjetivo gentílico, que por sua vez é derivado de base acrossêmica por sufixação, para designar os moradores da Assinalada Vila de São João Esmoler do Mar do Pavão; (b) corseado e reataviado, adjetivos como exemplos de neologismos formais; (c) funileiro e joanino, neologismos semânticos empregados no texto como adjetivo e substantivo, respectivamente, formados pelo processo de conversão. O exotismo de tais criações colabora para maior expressividade do que está sendo tratado.

Diferentemente do que ocorrerá ao longo da narrativa, quando o narrador recorrer ao discurso direto para ceder o turno da fala a algumas personagens, no capítulo selecionado para esta análise, o primeiro do romance, não são registradas palavras de baixo calão ou palavrões.

Ali a tradição vocabular atravessa um discurso culto, predominantemente formal, no qual são encontradas palavras construídas com o sufixo -al. Segundo Rodrigues 
Lapa (1998, p. 125), esse é um elemento de valor poético ou intelectual como em: universal, colossal, letal, abissal, abismal, infernal, financial, monumental, descomunal. Observa-se que nessa relação de adjetivos estão presentes duas formas concorrentes: abissal, de base grega, empregado em sentido figurado, e abismal, de base latina.

Com o sufixo -vel, tem-se indizível, incontável, irredutível, infindável, inesgotável e formidável, palavra cujo significado no texto transgride o sentido original - que inspira grande medo, pavor; assustador, aterrador. "Um diacronismo", diz o Dicionário Houaiss (2009), que se confirma semanticamente pela solidariedade das palavras que aparecem no enunciado, tais como negrume, encafuar, haja fugido, acovardada:

[...] A Lua deixa de existir e o horizonte se encafua para sempre no ventre do negrume, as escarpas da ilha do Pavão por vezes assomam à proa das embarcações como uma aparição formidável da qual não se conhece navegante que não haja fugido, dessa passando a abrigar a mais acovardada das memórias. (FIP, p. 9) [grifo nosso]

Outro caso interessante é o emprego do adjetivo "famígero", que recupera no texto o sentido de origem. A primeira acepção no Dicionário Houaiss (a partir de agora, DH) atribui ao item um aspecto semântico melhorativo: 
"o que leva ou traz novas, o que espalha notícias, o que é conhecido e esperado". No mesmo verbete há a remissão a "famigerado", que hoje tem acrescentado a seus sentidos possíveis o traço pejorativo, menos prestigioso, significando "tristemente afamado", mal visto ou malfeitor:

[...] a principal é de longe a Assinalada Vila de São João Esmoler do Mar do Pavão que, havendo sido pisada pela primeira vez por pé cristão num vinte e três de janeiro. Recebeu esse nome em honra do santo do dia, grande santo entre os mais santos [...] voz mais elevada das hostes de Malta, senhor da famígera cruz das oito pontas. (FIP, p. 15)

Algumas formas presentes no texto preenchem as características de compostos eruditos, tal como se apresenta a definição desse fato morfológico nos compêndios didáticos, formas como antropófagas e coprolalia, sendo esta um substantivo que pertence ao universo terminológico da psicopatologia, cujo significado é "tendência incontrolável a usar palavras obscenas", uma das malfeitorias do demônio Apolion.

A luta contra o Mal tem como um de seus representantes na ilha o mestre-escola e boticário Joaquim Moniz Andrade, aquele que "tem domínio da parenética" (FIP, p.17). Parenética é palavra erudita de origem grega e 
significa "ter eloquência religiosa, conhecimento dos discursos morais".

Há uma série de palavras em circulação cuja etimologia aponta a presença de empréstimos de variadas origens das quais o falante não se dá conta, assimilados que foram ao idioma, não mais sentidos como elementos estrangeiros. Vejamos algumas ocorrências:

1. Francesismos: ruante, surdir, boticas, bugres, coragem, miragem, taludes, oeste, frotas, chaminé, satânicos, sensações, franquear, frota divisa, feitiço, onça;

2. Espanholismos: forasteiro, menear, caudaloso, feiticeiras, forquilha, penha, tabaco, quiçá, atordoar, padecimento;

3. Italianismos: piloto, sentinela, cascata, comparsa, contraforte, irredutível;

4. Helenismos: prosélitos, demônio, falange, colossal, igrejas, caleças, meandros, caribdes, anarquia;

5. Germanismo: guisas;

6. Lusitanismo: capelista;

7. Arabismos: alcouce, amalgamado, açúcar, azeite.

A etimologia de algumas palavras mostra o quanto elas viajaram para chegar ao léxico da língua portuguesa. Este é 
o caso, por exemplo, da palavra botica, considerado em DH como uma forma diacrônica:

prov. fr. boutique < gr. apothêké, com a pronúncia bizantina apothíki; ver bodeg-; f.hist. 1460 butica, 1499 botiqua, sXV botica; ou caleça, registrada em $\mathrm{DH}$ como um regionalismo brasileiro: al. Kalesche (1636)'id.' (< checo kolesa, pl. de kolo 'roda'), pelo it. calèse (1691), pelo a.-fr. calège (1646) e pelo fr. calèche (1656). (HOUAISS, s.u.)

Outras pertenciam ao latim, mas nos chegaram por outras línguas. Por exemplo, caudaloso é etimologicamente descrita em DH como lat. capitalis, e 'que se refere à cabeça; que interessa à vida; capital; principal', segundo JM, pelo esp. caudal 'id'; ver capit-; f.hist. c1584 caudaes.

Tais formas reconstroem a formação do léxico português em território europeu, mas cuida o escritor de marcar o enriquecimento vocabular que as línguas conviventes no Brasil durante a colonização promoveram. A enumeração de signos designativos de elementos da natureza, fauna e flora, é um traço estilístico no romance de João Ubaldo Ribeiro principalmente na descrição dos ambientes que servem de espaço narrativo, recurso que firma e exalta as raízes brasileiras salpintadas com a cor local. 
À exceção de alguns regionalismos como entanguidos, engrolar, cavilosas e apicuns, as formas selecionadas fazem parte do vocabulário comum e circulam com certa frequência entre os usuários da língua ou, pelo menos, não causam tanto estranhamento ao leitor. Tal seleção constrói uma paisagem tipicamente brasileira com a presença de termos da fauna e flora locais.

8. Tupinismos;

9. Flora: sucupira, maçaranduba, jacarandá, ipês, jatobá, carnaúba, piaçava, apicum, oitizeiro;

10. Fauna: guará, jandaia, raposas, jaburu, preás, tatu, jararacas, teiús, jandaia, tucano, cobra-cipó, tamanduá, sanhaço;

\section{Africanismos;}

12. Fauna: macaco (or. controv.), marimbondo, calango.

São de origem tupi alguns topônimos encontrados no texto tais como Itacaranha, Itaparica, Pacu e Caçu, assim como outros, africanos, empregados para indicar a origem dos escravos que habitavam a ilha: Congo, Guiné, Benim, Oió, Daomé. De origem africana também é a palavra quilombo.

Ainda registramos os brasileirismos salpintados, entanguidas, sobrados, cavilosa, engrolar, gato-do-mato. Segundo o DH, aldeia é considerada um brasileirismo quando 
designa habitação indígena, como especialização semântica: aldeia (1500) Regionalismo: Brasil. Povoação habitada apenas por índios; maloca, aldeamento.

A exploração de campos léxico-semânticos auxilia significativamente a construção de sentidos do texto. Ao referir-se aos entes maléficos, os príncipes do Mal que surdem traiçoeiramente das trevas abissais para desencaminhar e levar à danação as inocentes criaturas de Deus (FIP, p. 10), a seleção lexical reúne adjetivos e substantivos que discursivamente assinalam comportamentos negativos, inferiores, criando uma ambiência ideal para explorar o tema, não se satisfazendo o escritor com a nomeação das entidades, apenas:

\begin{tabular}{|l|l|}
\hline \multicolumn{2}{|l|}{ Príncipes do Mal } \\
\hline $\begin{array}{l}\text { Oriax, Agares, Cassiel, Manon, Malquedama, Nimorup, } \\
\text { Apolion, Asmodeu }\end{array}$ \\
\hline substantivos & adjetivos \\
\hline $\begin{array}{l}\text { pesadelos, demônios, } \\
\text { miasmas, }\end{array}$ & $\begin{array}{l}\text { torpes, ardilosas, sulfurosos, } \\
\text { letais }\end{array}$ \\
$\begin{array}{l}\text { malfeitorias, padecimentos, } \\
\text { inveja, }\end{array}$ & lancinantes, maligno, abissal, \\
$\begin{array}{l}\text { despeito, entrega do corpo, } \\
\text { vícios, } \\
\text { dissipação, ganância, } \\
\text { coprolalia, } \\
\text { avareza, intolerância, ódio, } \\
\text { mentira, } \\
\text { trevas, diabos, estriges, lobos, } \\
\text { peidos }\end{array}$ & satânicos, luciferinos, \\
\hline
\end{tabular}


A presença de termos de especialidade é também observada. Pelo menos dois campos do conhecimento humano são ativados no texto pela presença de itens lexicais a eles pertencentes. Com relação aos termos de marinharia tem-se embarcação, navegante, velas, cascos, galeota, batelão, barco, ancoradouro, atracadouro, proa, pôr a pique, vagalhão, piloto, maré. Ao descrever a geografia detalhada da ilha estão presentes praias, ilha, ponta, enseada, angra, baía, lagoa, laguna, arrecifes, cascatas, morrotes. Ainda que no texto em análise as palavras mantenham o traço termo de especialidade, conforme registrado em $\mathrm{DH}$, a maioria delas se estendeu ao uso comum perdendo a característica de termo exclusivo.

Há o emprego de palavras que hiperbolizam os sentidos pretendidos, como os adjetivos na forma superlativa, crudelíssimo e altíssimo, ou explorando a camada sonora dos significantes na qual se incluem também adjetivos em -al, já assinalado, em -oso como caudaloso, numeroso e -ento em pachorrento.

Palavras como nordestezinho, chuvisquinho e brisazinha dão o tom coloquial ao último parágrafo do capítulo no qual o narrador descreve o amanhecer na ilha. Nessa passagem, itens eruditos ou formais cedem lugar às palavras 
de uso comum, talentosamente combinadas para pintar a rotina daquele lugar onde as mulheres ralam milho e coco e formigam em meio a gamelas e panelas (FIP, p. 18) ou cumprindo a missão que Ihe foi dada desde a Criação um grande bem-te-vi atitou energicamente na copa de um oitizeiro no Largo da Calçada (FIP, p. 18).

Conclui-se, então, pela amostragem, que João Ubaldo Ribeiro transita com sucesso pelos diferentes vocabulários na construção dos sentidos do texto, mantendo a coerência entre texto e intenção discursiva. As palavras são pistas a serem seguidas para percorrer as trilhas traçadas pelo escritor. Considera-se, também, de que maneira a leitura de textos literários pode contribuir de forma relevante para a ampliação do vocabulário dos leitores, acatando o pensamento de Antunes (2010, p. 178) que afirma: um repertório amplo e diversificado é condição de uma atuação comunicativa socialmente participante, funcional e relevante.

Destacamos ainda o valor do trabalho com o manuseio de dicionários que, nesta pesquisa, foi de importância crucial na descoberta não só da origem das palavras, mas, em muitos dos casos da resistência semântica de algumas formas e da exposição à mudança de sua significação ao longo do tempo, assim como o cuidado do escritor em usar determinados 
itens lexicais explorando a primeira significação arrolada nos dicionários gerais. $\mathrm{E}$ a redescoberta prazerosa de nossas origens veio pelas muitas formas usadas no texto de João Ubaldo e que fazem parte de nosso cotidiano, legadas ao léxico da língua por índios, negros africanos e quem mais influenciou nossa cultura.

Não só no capítulo que nos serviu de córpus para a análise realizada, mas em todo o romance, o trabalho vocabular de João Ubaldo Ribeiro demonstra que não é pertinente julgar-se um texto como menos formal apenas porque dele fazem parte palavras de menos prestígio social, ou desgastadas pelo uso frequente. A predileção por itens lexicais ligados à tradição não exclui do romance o vocabulário popular representado pelas palavras de uso comum. Para um escritor de que se sabe leitor de grandes obras, detentor de formação intelectual das mais consideradas, produzir uma narrativa que transita pelos diferentes usos da língua, do mais formal ao mais informal deve ser trabalho de árdua elaboração, cujo resultado é a qualidade literária que encontramos em seus livros.

\section{REFERÊNCIAS}

Antunes, Irandé. (2010). Análise de textos: fundamentos e práticas. São Paulo: Parábola Editorial.

Holanda, Aurélio Buarque de. (2014). Novo Aurélio Século XXI: dicionário da língua portuguesa (Rev. 5a ed. e ampl.). Curitiba: Editora Positivo. 
Houaiss, Antonio. (2009). Dicionário Houaiss da língua portuguesa. Rio de Janeiro: Objetiva.

Lapa, Manuel Rodrigues. (1998). Estilística da Língua Portuguesa (4a ed.). São Paulo: Martins Fontes.

Ribeiro, João Ubaldo. (1997). O feitiço da ilha do Pavão. Rio de Janeiro: Nova Fronteira.

Santos, Denise Salim. (2008). Tradição e transgressão: um estudo do vocabulário em $\mathrm{O}$ feitiço da ilha do Pavão (dig.). Rio de Janeiro: UERJ.

Denise Salim Santos - Atua no mestrado de Língua Portuguesa e em turmas de graduação. Membro integrante do GT de Lexicologia, Lexicografia e Terminologia da ANPOLL. Publicação: "Língua Portuguesa descrição e ensino: diálogos", (org.) 2012.

Contato: d.salim@globo.com 